www.jmscr.igmpublication.org

Index Copernicus Value: 79.54

ISSN (e)-2347-176x ISSN (p) 2455-0450

crossref DOI: https://dx.doi.org/10.18535/jmscr/v7i5.143

\title{
Staining Acid-Fast Bacilli in Sputum Containers by Selvakumar et al. Method
}

\author{
Authors \\ Swapna Sasapu ${ }^{1}$, Nitin Mohan ${ }^{2 *}$, I. Jyothi Padmaja ${ }^{3}$, P Hema Prakash Kumari ${ }^{4}$ \\ K. Suresh ${ }^{5}$ \\ ${ }^{1}$ Assistant Professor, Department of Microbiology, GITAM Institute of Medical Sciences and Research \\ ${ }^{2}$ Assistant Professor, Department of Microbiology, GITAM Institute of Medical Sciences and Research \\ ${ }^{3}$ Professor, Department of Microbiology, GITAM Institute of Medical Sciences and Research \\ ${ }^{4}$ Professor \& HOD, Department of Microbiology, GITAM Institute of Medical Sciences and Research \\ ${ }^{5} \mathrm{PhD}$ Research scholar, Dept. of Microbiology and FST, GITAM Institute of Sciences \\ GITAM (Deemed to be University), Visakhapatnam-530045 (A.P), India \\ Website: www.gitam.edu \\ *Corresponding Author
}

\section{Dr Nitin Mohan}

Assistant Professor, Department of Microbiology, GITAM Institute of Medical Sciences and Research, GITAM (Deemed to be University), Visakhapatnam-530 045, Andhra Pradesh, India

\begin{abstract}
Introduction: Making direct smears from sputum is considered risky for personnel. In reference laboratories where multi-drug resistant tuberculosis is routinely diagnosed, smears are made from the concentrated deposits after processing sputum samples. Deposit smears generate aerosols \& may also get peeled off from slides. The aim of this study was to stain the sputum centrifuged deposits obtained by ZiehlNeelsen method \& Selvakumar et al. method and compare.

Materials \& Methods: According to Selvakumar et al. method deposits of 116 decontaminated and homogenized sputum samples in sputum containers were stained with $1 \mathrm{ml}$ of $1 \%$ carbol-fuchsin between 2 to $3 \mathrm{~h}$, and their smears made subsequently on glass slides were decolourized with $25 \%$ sulphuric acid and counterstained with 1\% Methylene blue for detection of AFB under a light microscope as in Ziehl-Neelsen method.
\end{abstract}

Results: The sensitivity and specificity of $2 \mathrm{~h}$ stained deposit was $92.4 \%$ and $97.3 \%$. The results of $2 \mathrm{~h}$ stained deposit were comparable (kappa $=0.84$ ) to initial deposit smears.

Conclusions: Selvakumar et al. method was in agreement with the gold standard Ziehl-Neelsen method. Sputum deposit treated with carbol-fuchsin in containers render it non-hazardous. Staining procedure is simple.

Keywords: Acid-fast bacilli, Ziehl-Neelsen staining, Selvakumar et al. method, chi-square test.

\section{Introduction}

For presumptive diagnosis of pulmonary tuberculosis, direct microscopy for finding of acid-fast bacilli (AFB) in sputum specimens still is the key tool in numerous countries..$^{(1,2,3)}$ The possible danger of laboratory work with 
Mycobacterium tuberculosis is well documented. $^{(4)}$ Reports of laboratory-acquired tuberculosis (TB) infections, with aerosols and skin punctures being the most frequent reported routes of transmission are available. ${ }^{(1,4)}$ In general, making smears from sputum is risky for personnel working in developing countries with inadequate facilities. ${ }^{(1,4)}$ With the involvement of private sector in Revised National Tuberculosis Control Programme the onus for the diagnosis and monitoring of the tuberculosis patient has also shifted to laboratories not specialized in mycobacteriology. ${ }^{(5,6)}$ A lot of laboratories now usually collect and microscopically examine clinical specimens for acid-fast bacilli. $^{(6)}$ In laboratories with inadequate facilities, the specimen may be sent to a reference laboratory for culture. ${ }^{(6)}$ With the implementation of Universal Drug Susceptibility testing, has resulted in an rising amount of specimens and cultures being processed in reference laboratories, thus increasing the possibility of accidental contact for laboratory workers. ${ }^{(4,7)}$ In reference laboratories, smears are made from the concentrated deposits after processing sputum samples for culture. ${ }^{(1,8)}$ These deposit smears, in addition to generating aerosols, often get peeled off from the slides, resulting in false negative results. ${ }^{(1)}$ A new technique both simple and non-hazardous to stain the AFB has been described by Selvakumar et al. $^{(1)}$

The aim of this study is to stain the sputum centrifuged deposits obtained by $\mathrm{N}$-acetyl Lcysteine -sodium hydroxide (NALC-NaOH) method with Ziehl-Neelsen method and Selvakumar et al. method and compare.

\section{Materials and Methods \\ Preparation of Reagents}

For preparation of $1 \%$ carbol-fuchsin, $5 \mathrm{~g}$ of basic fuchsin dye (Qualikems, Delhi, India) was added to $50 \mathrm{ml}$ of methylated spirit, 25 grams of phenol (Nice, Kochi, India), and distilled water to make up a final volume of $500 \mathrm{ml}$. For preparation of $25 \%$ sulphuric acid $125 \mathrm{ml}$ of concentrated sulphuric acid was added slowly into the flask containing $375 \mathrm{ml}$ of distilled water. For preparation of $0.1 \%$ methylene blue solution, 0.5 grams of methylene blue (Qualikems, Delhi, India) was added to $500 \mathrm{ml}$ of distilled water.

\section{Sputum Samples Processing}

A total of 116 sputum samples from patients of pulmonary tuberculosis which were submitted for diagnosis as well as for follow up examination at a Designated Microscopy Center attached to a Medical College were included in the present study. The sputum samples were subjected to digestion and decontaminated by NALC-NaOH method. ${ }^{(9)}$ Smears were made from the sputum deposits thus obtained. Handling and preparation of smears from sputum samples were performed in a Class II biological safety cabinets. ${ }^{(10)}$ Figure-1 showed the overall procedures employed in the current study.

\section{Ziehl-Neelsen Staining}

Initial deposit smears were made by uniformly spreading on a glass slide one loop full $(5 \mathrm{~mm}$ diameter disposable plastic loop) of sputum deposit followed by air drying it for 15-20 min and fixing it over a hot plate at $80^{\circ} \mathrm{C}$ for $15 \mathrm{~min}$. The initial deposit smears were then stained by Ziehl-Neelsen method. ${ }^{(1,10,11)} 1 \%$ Carbol fuchsin was poured to cover the entire surface of the slide and heated from underneath until vapors start rising and kept for $5 \mathrm{~min}$. The slides were then rinsed gently with water. $25 \%$ sulphuric acid was poured onto the slides and left to stand for 2-4 minutes in order to decolorize. After rinsing with water $0.1 \%$ methylene blue was added and left for $30 \mathrm{sec}$ in order to counterstain. After washing and air drying the smears were examined under oil immersion lens.

\section{Selvakumar et al. Staining Method}

Two hour stained deposit smear was prepared according to procedure specified by Selvakumar et al. ${ }^{(1)}$ To the remaining deposit in the falcon tube, $1 \mathrm{ml}$ of $1 \%$ carbol fuchsin was added and 
kept for 2-3 h, subsequently a smear was made and immediately heat fixed by passing over the flame 5-6 times. Decolourization and counterstaining followed using the same procedure and reagents.

\section{Smear Reading and Statistical Analysis}

Coded initial deposit smears and $2 \mathrm{~h}$ stained deposit smears were read by same reader and results compared. The results of initial deposit smears were considered as gold standard. The statistical significance of the observed difference between the different types of smears was determined using chi-square test.

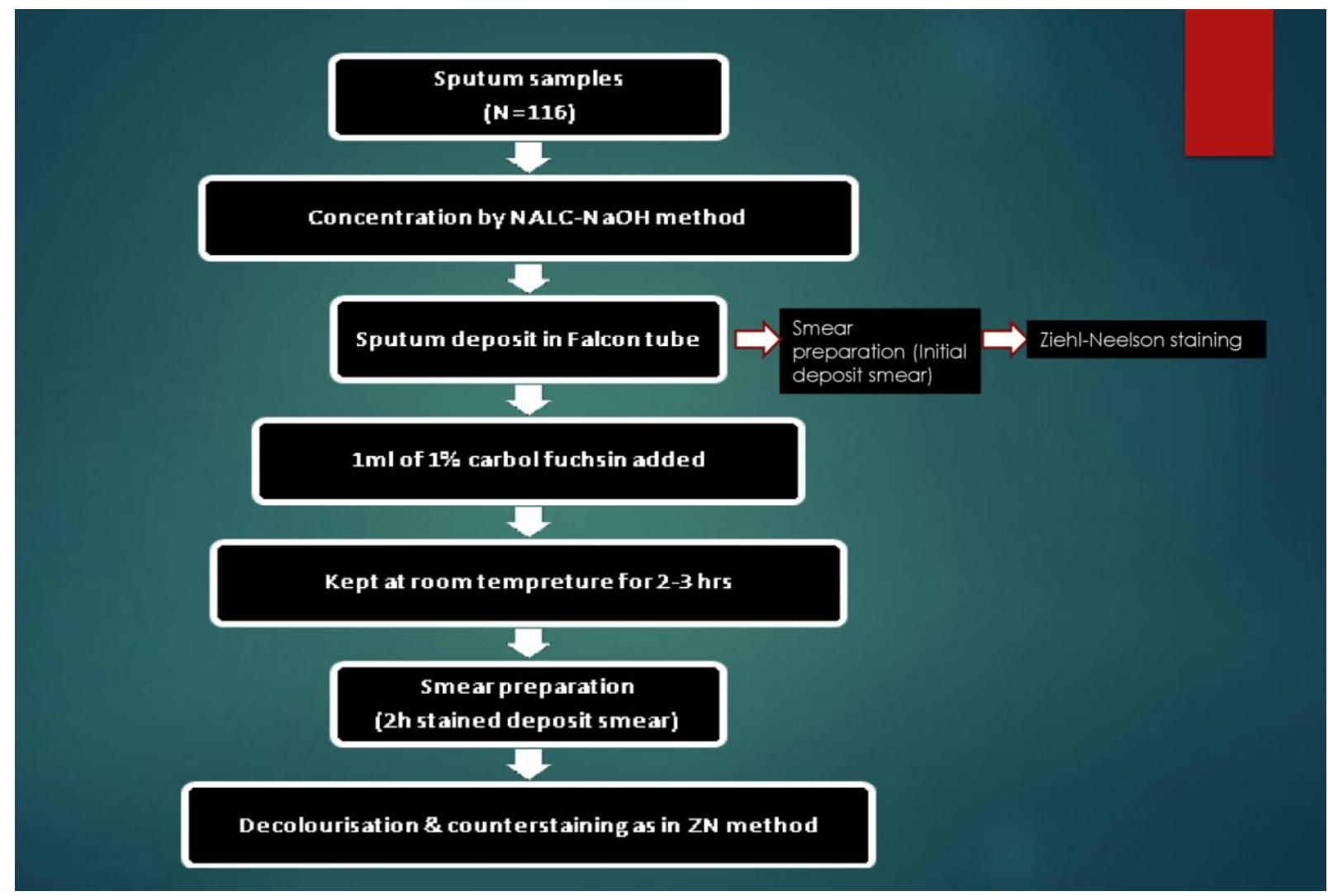

Figure 1: Flow chart showing overall methodology of the present study

\section{Results}

Table 1: Comparison of smear results

\begin{tabular}{|l|l|c|c|c|}
\hline \multicolumn{2}{|c|}{ Smear results } & \multicolumn{2}{|c|}{$\begin{array}{c}\text { Initial deposit smears } \\
\text { (Ziehl-Neelsen Method) }\end{array}$} & \multirow{2}{*}{ Total } \\
\cline { 2 - 4 } \multicolumn{2}{|c|}{} & Positive & Negative & \\
\hline \multirow{2}{*}{$\begin{array}{c}\mathbf{2} \text { h deposit smears } \\
\text { (Selvakumar et al. method) }\end{array}$} & Positive & 73 & 1 & 74 \\
\cline { 2 - 5 } & Negative & 6 & 36 & 42 \\
\cline { 2 - 5 } & Total & 79 & 37 & 116 \\
\hline
\end{tabular}

The sensitivity and specificity of $2 \mathrm{~h}$ stained deposit was $92.4 \%$ and $97.3 \%$. The results of $2 \mathrm{~h}$ stained deposit were comparable $(\mathrm{kappa}=0.84)$ to initial deposit smears. The differences observed were not significant $(\mathrm{p}<0.05)($ Table-1).

\section{Discussion}

Selvakumar et al. reported agreement between $2 \mathrm{~h}$ stained deposit smear and initial deposit smears in detection of acid fast bacilli $(\mathrm{k}=0.89)$ in their study done at National Institute for Research in Tuberculosis (formerly TRC), Chennai. ${ }^{(1)}$ They 
reported a sensitivity and specificity of $93 \%$ \& $96 \%$ which is comparable to present study.

Tuberculosis among laboratory workers is more common than in the general population. ${ }^{(4)}$ Low infective dose of Mycobacterium tuberculosis for humans rend all sputa from patients with TB must be potentially infectious. ${ }^{(4)}$ With increasing isolation of multidrug-resistant strains of Mycobacterium tuberculosis in reference laboratories in India and the increased workload of specimens because of implementation of Universal DST in these laboratories the danger of laboratory acquired tuberculosis infections is enhanced. ${ }^{(4) 7)}$ Of all the reported laboratory acquired bacterial infections, $44 \%$ are due to Mycobacterium tuberculosis. ${ }^{(4)}$ Aerosols generated during sputum processing and culture manipulations are more common cause of tuberculosis in laboratory acquired infections than cutaneous injury. ${ }^{(3,4)}$ In most cases, source of infection remains unknown and unstained smears have never been implicated as a source. ${ }^{(4)}$ But many authors have demonstrated it as a potential source of infection. ${ }^{(2,3,4)}$

Many methods were tried to make the process of smear preparation and acid fast staining for diagnosis of tuberculosis safer. ${ }^{(2,3,4)}$ Heat fixing air dried smear material either by passing slide through the flame or using a hot plate does not kill Mycobacterium tuberculosis. ${ }^{(2,3,7)}$ So heat fixing need to be carried out in a bio safety cabinet. But use of flame in a bio safety cabinet is not advisable and using a hot plate (2 hours at $65 \mathrm{OC}$ ) is cumbersome and time consuming if specimen load is huge. ${ }^{(4)}$ Staining methods like ZiehlNeelsen render smear safe. ${ }^{(1,3,4)}$ Alcohol and phenol both ingredients of carbol-fuchsin are tuberculocidal. $^{(3,4)}$ But staining requires sink and hence is performed outside the bio safety cabinet. ${ }^{(4)}$ There is risk of infection if slide are broken or if material flakes of the slide during removal of from bio safety cabinet ${ }^{(1,3,4)}$.

The Selvakumar et al. method of acid fast staining provide many advantages and claims to make smears less hazardous by treating deposit with carbol-fuchsin for $2 \mathrm{~h}$ in the sputum container itself in a bio safety cabinet where digestion and concentration procedure has been performed. ${ }^{(1)}$ The prolonged duration of contact with carbolfuchsin inactivates bacilli in spite of concentrated sputum containing high organic load \& high lipid content of the cell wall. ${ }^{(1,2)}$ The prolonged contact period may be an advantage where in the routine work flow smear cannot be stained immediately by Ziehl-Neelsen method and where samples are pooled till the last patient has been examined..$^{(1,3)}$ Heat fixing can be performed outside bio safety cabinet by passing it over a flame. Heat fixed smear are safer for transport to sink and performing decolorization and counterstaining. ${ }^{(4)}$ Sputum containers become less contagious and disposal becomes easier. ${ }^{(1)}$ When compared to Ziehl-Neelsen method, Selvakumar et al. method is simpler. It does not require heating of carbolfuchsin. So there is no drying of stain and disfigurement of acid fast bacilli is avoided. ${ }^{(1)}$ The amount of carbol- fuchsin required is also reduced. ${ }^{(1)}$ The disadvantage of Selvakumar et al. method is that it can only be applied on deposits of sputum samples which are obtained by using a high speed centrifuge available in reference laboratories.

\section{Conclusion}

In conclusion the results of Selvakumar et al. method were in agreement with the gold standard Ziehl-Neelsen method. Sputum deposit treated with carbol-fuchsin in containers for at least $2 \mathrm{~h}$ stain acid fast bacilli and renders it nonhazardous. Staining procedure is simples and requires less consumable. Safety precautions should be followed in laboratories performing diagnosis of tuberculosis.

The study was not supported by any grants and funds and declared "No conflict of interest"

\section{References}

1. Selvakumar N, Ravikumar D, Sivagamasundari S, Gopi PG, Narayanan 
PR. A novel method of staining acid-fast bacilli in sputum containers. Indian J Med Res 2006: 123: 776-780.

2. Giacomelli LRB, Helbel C, Ogassawara RLN, Barreto AMW, Martins FM, Cardoso CL, Leite CQF. Improved Laboratory Safety by Decontamination of Unstained Sputum Smears for Acid-Fast Microscopy. Journal of Clinical microbiology 2005: 43: 4245-4248.

3. Cardoso CL, Giacomelli LRB, Helbel C, Sant'Ana JJ, Martins FM, Barreto AMW. Survival of Tubercle Bacilli in Heat-fixed and Stained Sputum Smears. Mem Inst Oswaldo Cruz, Rio de Janeiro2001: 96: 277-280.

4. Chedore P, Th'ng C, Nolan DH, Churchwell GM, Sieffert DE, Hale YM, Jamieson F. Method for Inactivating and Fixing Unstained Smear Preparations of Mycobacterium tuberculosis for Improved Laboratory Safety. Journal of clinical microbiology 2002: 40: 4077-4080.

5. Anand T, Babu R, Jacob AG, Sagili K, Chadha SS. Enhancing the role of private practitioners in tuberculosis prevention and care activities in India. Lung India 2017: 34:538-44.

6. Goldfogel GA, Sewell DL. Preparation of Sputum Smears for Acid-Fast Microscopy. Journal of clinical microbiology 1981: 14: 460-461.

7. Chatterjee S, Poonawala H, Jain Y. Drug resistant tuberculosis: Is India ready for the challenge. BMJ Glob Health 2018: 3:e000971: doi:10.1136/ bmjgh-2018000971

8. RNTCP training manual for Mycobacterium tuberculosis Culture and Drug susceptibility testing. New Delhi: Directorate General of Health Services: 2009

9. Kent PT, Kubica GP. Public Health Mucobacteriology - A guide for the level
III laboratory. CDC, Atlanta, Georgia: 1985.

10. Standard Operating Procedure for Mycobacteriology Laboratory.

Tuberculosis research Centre, ICMR, Chennai: 2010.

11. Revised National Tuberculosis Control Programme (RNTCP). Manual for Laboratory Technicians. Central TB Division. Directorate General of Health Services, Ministry of Health and Family Welfare. New Delhi, India: 2005: (http://www.tbcindia.org/LABMANUAL. pdf). 